\title{
A Virtual Learning Environment Development. Some Experiences at the University of La Plata
}

\author{
Cecilia Sanz ${ }^{1}$, Alejandro Gonzalez ${ }^{1}$, Alejandra Zangara ${ }^{2}$, Eduardo Ibañez ${ }^{1}$, \\ Luciano Iglesias ${ }^{1}$ and Armando De Giusti ${ }^{1}$ \\ ${ }^{1}$ Faculty of Computer Science, University of La Plata, Buenos Aires, Argentina \\ ${ }^{2}$ Faculty of Education, University of La Plata, Buenos Aires, Argentina
}

E-learning is a new and rapidly evolving discipline. Particularly, e-learning environments have become a topic of research and study. This paper presents an investigation related to e-learning and the development of virtual learning environment (WebINFO) made by an interdisciplinary team at the University of La Plata. Some experiences within university scope using this kind of technology are also presented.

Keywords: e-learning, virtual learning environment, pedagogy.

\section{Introduction}

E-learning refers to using electronic applications and processes to learn. E-learning applications and processes include Web-based learning, computer-based learning, virtual classrooms, and digital collaboration. Contents can be delivered via the Internet, intranet/extranet, audio or video tape, satellite TV, and CD-ROM $[1][2]$.

One of the main advantages of e-learning is that students can learn with no time and distance constraints. They can interact with their teachers by means of e-mail, chat, etc.

Virtual Learning Environments provide different tools to achieve the main goals of a learning process. Most of them allow working with communication, contents, collaborative and assessment tools. Teachers can customize them in order to create their own courses. Students access this environment and they can follow the course, maintaining their progress and interacting with the tutors, among other things [3][4].

However, there is a growing number of this kind of environments (commercial and non commercial), which do not take into account pedagogical aspects.

WebINFO is a result of a project related to technology and education, which has been developed at the Faculty of Computer Science (University of La Plata). It is an e-learning environment in the web, with three main goals:

- It must follow a methodological process to design distance courses

— It must follow a pedagogical model

- It must be easy to use both for teachers and students.

In order to accomplish these objectives an interdisciplinary group was created, with people from the education area, the graphical design area, and the computer science area.

The first stage of this project was to elaborate a common communication protocol among the members, due to the problems related to the specific vocabulary of each one [5]. Later, a pedagogical model was developed based on constructivist and cognitive theories. In addition to this, different web learning environments were analyzed and compared. For this, some metrics were taken into account.

In the following sections, details of this process and a WebINFO description are presented. 


\section{WebINFO, Main Decisions}

In the context of this project, new technologies are studied from a pedagogical model so as to transform the learner's environment in a learning situation [6][7].

Consequently, the question of how to reflect these ideals in the developed learning environment is being analyzed.

A methodological proposal to guide the construction process of courses has been developed in a virtual learning process.

According to this methodology, the design of a course in WebINFO is oriented with pedagogical units called AREAS.

These areas are:

— Introduction / Welcome

- General Information and Contents

- Communication

— Educational Resources

- Collaborative Work

- Practical Work and Evaluation

- Administration and Tracking

Each of these areas has a specific objective and guides the teacher in the structuring process of the course so as to ease the new roles that are to be played by teachers in the teaching-learning process.

These areas are made up of sections and tools. The sections are divisions that are present in some areas in order to organize the tools.

Finally, the tools are referred to as teaching and communication instruments allowing teachers to fulfill their proposal.

The process that a teacher should carry out for the construction of his/her distance course is that of taking decisions in each of these areas, which consist of reflecting, by means of their particular tools, the structure of his/her course. For example, in the Communication area, a teacher should determine how tutors will assist students, and which interaction tools will favor communication among students within his/her course. In WebINFO, all these decisions will be accompanied by examples and textual aids based on the experiences of expert teachers in distance education.

\section{Areas of WebINFO}

Introduction/Welcome Area: its purpose is to introduce students into the process, giving them an explanation of how to start, and creating a friendly atmosphere.

Communication Area: it is the place in WebINFO where the interaction and communication occur. Teachers have to decide which tools they need for their courses and they have to incorporate them. They can select an asynchronic message interchange, a tool to create discussion forums, and a tool to publish news. Besides, we are implementing a synchronic tool for virtual meetings (chat, video, audio) which will be available soon $[8]$.

General Information and Contents Area: one of the areas considered of great importance is that of General Information and Contents, which proposes a guided organizing work of the information so that the teacher - at the time of designing the course - is accompanied by the proposal of the environment.

A teacher should think of incorporating the tools that represent the objectives, methodology, schedules and information about the teaching staff, and of determining thematic units for his/her own course as well as of incorporating the material for each of these units.

In WebINFO, each unit may present different criteria of visibility which will allow generating various work circuits for the different students (this is not available for all platforms known so far). For example, a certain unit may be viewed only by a given group of students that has not passed an input evaluation, and whose purpose consists in homogenizing the required knowledge for doing the course. This could be related to certain learning theories which state that the learning process has to be adjusted individually; if you give more contents than the student can assimilate at a particular moment, the student will have problems. On the other hand, if you give less content, students may get bored. With this purpose in mind, WebINFO allows different paths to the table of contents of the course in order to satisfy personal requirements. 
Collaborative Work Area: the objective of this area is to provide both teachers and students with the possibility of working in groups, in a collaborative manner. There are several tools that a teacher could select for his course. For example, he may use the one that allows each student to incorporate personal information in order to introduce him/her to the rest of the group. The information given by each group member makes it possible to create a common place to share information about themselves, their photos, etc.

Another tool is the one that allows group formation. It is possible for a teacher to create groups with coordinators and tutors. There are different ways to assign students to a group. Each group can have a description and a presentation.

Finally, there is a tool for sharing files among all the members of the course or only for the members of one specific group [9].

Educational Resources Area: its purpose is to provide teachers and students with additional tools such as a glossary, faqs management, media library, etc.

Practical Work and Evaluation Area: another area of special attention is that of Evaluation; it is generally difficult to design this area, and the creation processes of evaluations in learning environments may be messy for teachers. A construction of the evaluation instances of a course in consecutive steps has been designed, in which the teacher can determine the type of evaluation (auto-evaluation, compulsory practical works, exams), define the aspects related to marking and grading, the way of distributing questions, project deadlines, etc. Finally, work is being done on the selection or construction of questions, where the teacher may take previously designed questions for his/her courses or may create a new one. The questions may be of different types (selection, long and short answer, matching, etc.). WebINFO has made an attempt to include a varied collection of question types from which the professor may choose. This area was carefully analyzed by the team paying special attention to the teacher's point of view, the evaluation process theory, and security aspects.

Administration and Tracking Area: this area has a tool that can help teachers in their administration tasks and in tracking tasks as well.
Tools in this area are: students' administration and tracking, teachers' administration and tracking, course administration, and statistics for the course. It is possible through these tools to know when a certain student/teacher logs into the course for the first and last time, which tool he/she used specifying date and time, how many messages he/she wrote (distinguished by recipient: to students or to teachers, or both), how many messages he/she received, and how many of them have been replied, etc. In addition, the statistics tool allows different kinds of general statistics for the course, such as participation ranking for forums, number of exchanged messages, etc.

\section{Scenarios}

A teacher may opt to choose a working scenario predetermined for his/her course. A scenario constitutes a template that incorporates a set of tools in the different areas of a course. For example, a teacher may want to work with a course only with communication tools and, for it, he/she counts with a scenario "rich in communication" so that, if it is to be chosen, he/she will already count with pre-selected tools necessary for the communication in the corresponding area. This will ease the teacher's tasks in the design of the course.

In brief, there will exist various scenarios so that the teacher is able to initiate with a predefined design of his/her course. In these predetermined scenarios, areas appear by definition and the tools of each area are already selected. These scenarios are defined taking into account possible types of designs that the teacher may need, and help them to create blended or distance learning courses. The areas and tools of each of them are related to the type of need to be fulfilled. If the professor prefers to work without predetermined options, he/she can select a free scenario. The free scenario is that in which the teacher may choose his/her desired tools from the design areas. For example, in some cases, a teacher may only need to enrich the communication process of the course, and decide to use the environment for this purpose so she/he could choose the communication scenario in which the course has all the communication tools preselected. 


\section{Designing a Blended Learning or Distance Courses in WebINFO}

Designing of a course can be divided in three stages: 1) selection of a work scenario (it can be a free scenario); 2) working by areas, allowing the teacher to properly concentrate on the planning of the communication within his/her course, how the contents will be presented and how the students will access such contents (he/she will be able to pose different pathways according to the students' profiles), which type of evaluation will be incorporated and what type of work or activities will be required, and which collaborative activities will be incorporated; 3 ) selection of proper tools of each area.

Teachers have to determine the best tools for their context, target students, and the particular situation they are involved in. It is very important to define the appropriate educational strategies and then design the course accordingly.

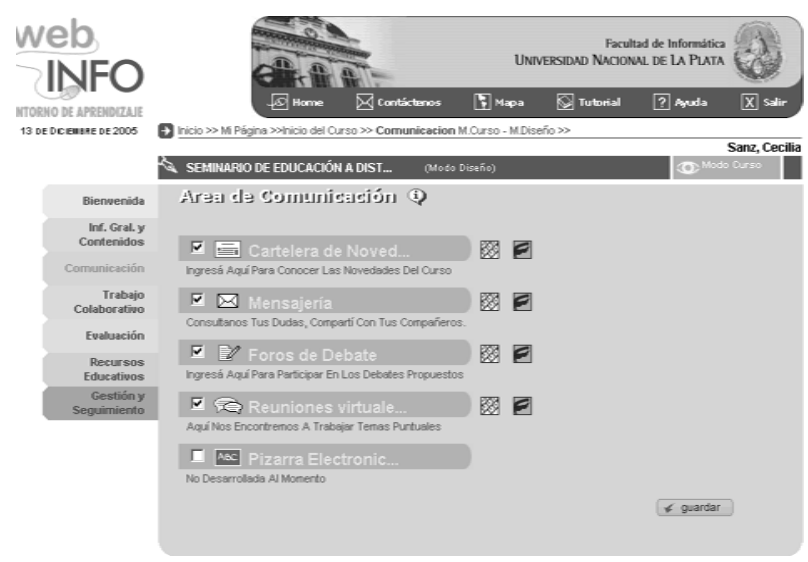

Fig. 1. This is an example of the communication area in WebINFO.

The whole process will be guided by the environment by way of proper examples and assistance elements.

There is a tutorial that guides teachers and students tasks with flash animations; besides, there is a text manual for students, enabling them to learn how to work with WebINFO.

\section{Experiences with WebINFO at the University of La Plata}

WebINFO has been used in different areas at the University of La Plata. Some of these experiences are presented below in order to show examples of how different tools in WebINFO are used. Each experience was analyzed and evaluated by means of interviews and surveys to the teachers and students involved.

\subsection{Introductory Course for the Faculty of Computer Science}

Every year around 600 students attend an introductory course whose main purposes are to prepare students for their first year at university, giving them the topics necessary to begin the first year, and integrate them into university level. Many of these students are from different cities of Argentina, and have to travel to attend this course at the very beginning of February. The course takes place during February and March.

Last and the current year, a distance course was designed to give the option to students to be prepared without attending the course in La Plata. Specific materials were designed to give the necessary contents to students, and a group of tutors were assigned to guide students in this experience. WebINFO was used as the virtual environment where the communication and the content access took place. Teachers decided to incorporate the following tools in WebINFO:

- Messaging Tool: so that students and teachers can send messages with questions and activities required to pass the course.

- Board News: here teachers publish the news of the course, such as new material available, the date of a certain activity, etc.

- General Information: objectives, methodology, schedules, and teachers personal information.

- Table of Contents: each unit was presented here with the corresponding material to read or study. Besides, some activities were incorporated.

- Glossary: technical vocabulary was incorporated in a multimedia glossary. 
Students can access the next unit once they have passed the corresponding activity in the previous one. This was done using the visibility tool in the General Information and Content area.

Once students have passed the different units, they have to take a presence exam. Those who pass the exam do not have to do the traditional presence course.

It is important to underline that most of the students that attended the distance course passed the exam and they had a very good performance during the first year at university. There is a group of people evaluating the impact of this course on students.

\subsection{Software Engineering Course at the Faculty of Computer Science}

This is a course of the third year of the Computer Science Licentiate Degree of the Faculty of Computer Sciences

The course proposes a software engineering project development. Students have to work in groups of four members to develop this project.

The project is based on the topics given by the teachers during the course.

Due to the project process, which implies the communication among the members of the group, the documentation interchange, and the document presentation required by the teachers, WebINFO was used to support all these tasks.

The Collaborative Work Area was used to form the groups, to assign a tutor to each group, and finally to share information among the members using the Sharing File Tool of this area.

Each group had to upload their documents in a repository which was private for the group and the tutor. The tutor could see who was responsible for making each document, and follow the process. Tutors had to evaluate the documents and gave the results to the students following the same methodology.

Some forums were also designed to discuss with each group about how they would implement the project (for example which data base engine and program language they would use).

A survey was designed to evaluate the methodology proposed for the course. Students said that they found advantages working with WebINFO, because they could work in groups in a more flexible way, they could register all the process in the same environment, and teachers could follow and help them.

\subsection{Distance Education Seminar. Master in Computer Technology Applied to Education at UNLP}

This Seminar proposes a blended learning process which starts with a meeting with all the students during which the teachers introduce themselves. They explain the methodology proposed by the course and present the schedule. Each student also exposes his/her interests in the course, and his/her expectations.

WebINFO is also used to mediate the communication, to motivate the participation of students, and to present contents and activities.

Last year, some texts were presented and discussed using such virtual environment. With this purpose, several forums were developed. These forums were scheduled with an explicit objective, shown by the teachers through the corresponding tool in WebINFO. In this way, the bases for the discussion were set. They could also create public or private debates. The public ones allowed participation of all members of the course, while the private ones only allowed participation of those designated by the teacher to take part in the debate. The teacher could block or stop the debate, in order to close the interchange of opinions. This could be accomplished by setting the property block in the corresponding debate in WebINFO. For this Seminar during 2004, three debates were developed. The first one was evaluated and guided by teachers. There were 8 groups discussing different specific topics simultaneously on the basis of the textual materials of the course. Each student had to expose his/her opinion about the topic of discussion and justify it with the texts contents.

Other debates were designed with different purposes: the second was meant for students to present personal experiences with reference to the topics of discussion, and the third one was dedicated to the discussion about the final project they had to implement. 
Students have reported that this type of experiences enriched the course and the interaction, particularly when they were geographically distributed.

\section{Conclusions and Further Work}

There is no doubt that e-learning and virtual learning environments have been revolutionizing our way of learning as well as teaching. By these means we are overcoming distance and time constraints. However, pedagogical strategies must be carefully defined.

A virtual learning environment developed at the Faculty of Computer Science of UNLP was presented here. This environment develops a pedagogical model, designed by an interdisciplinary group. Some of the main characteristics of this environment were discussed.

Finally, some experiences were analyzed in order to emphasize the possibilities of WebINFO.

Some of the future work we are planning involves incorporating more functionality to the environment, such as synchronic tools for communication and continuing with teachers training in this kind of experience.

Besides, the environment will be adapted to SCORM standard.

\section{Acknowledgements}

The authors would like to thank Eng. Armando De Giusti for his support in this process and the teachers that have contributed with information about their experiences.

\section{References}

[1] RosenBerg, M., E-LEARNING. Estrategias para transmitir conocimiento en la era digital. Colombia: Mc Graw Hill, 2001.

[2] CABERO B., Nuevas Tecnologías aplicadas a la Educación. Madrid: Editorial Síntesis, 2000.

[3] ABBey B., Instructional and Cognitive Impacts of Web-Based Education. London: Idea Group Publishing, 2000.
[4] BEER V., The Web Learning Fieldbook: Using the World Wide Web to Build Workplace Learning Environments. San Francisco, California (USA): Jossey-Bass / Pfeiffer, 2000.

[5] SAnZ C., Zangara A., GonZalez A., IBÁÑEZ E., DE GIUSTI, A., Diseño de cursos no presenciales en un Entorno de Aprendizaje en la Web (WebLIDI). Proceedings of IX Congreso Argentino de Ciencias de la Computación; 2003. Argentina. La Plata: University of La Plata.

[6] Sanz C., Madoz C., Gorga G., Zangara A., GONZALEZ A., IBAÑEZ E., DE GIUSTI A., Entornos de aprendizaje en la Web. Experiencias con WebLIDI. Proceedings of Workshop de Investigadores en Ciencias de la Computación, 2004. Argentina. Neuquén.

[7] KAPLUN M., Los materiales en la Educación a Distancia. Buenos Aires. Asociación Argentina de Educación a Distancia. Fundación Banco de Boston. 1989.

[8] FAINHOLC B., La interactividad en la Educación a Distancia. Buenos Aires: Paidós. Cuestiones de Educación, 1999.

[9] HANNA D. E. ET AL., 147 Practical Tips for Teaching Online Groups: Essentials of Web-Based Education. USA: Atwood Publishing, 2000.

[10] Burbules N. y CAllister T., Riesgos y promesas de las Nuevas Tecnologías de la Información. Buenos Aires: GRANICA - Educación., 2001.

[11] CHACON, F., Mind-Mapping for Web Instruction and Learning. Franciscan University of Steubenville, 2003.

[12] Tiffin J. Y RagAsingham L., En busca de la clase virtual. La educación en la sociedad de la información. Barcelona, Buenos Aires, México: $1^{\text {ra }}$ Edición. Ediciones Paidós, 1997.

[13] Bransford J., Brown A. Y Cocking R., How people learn. USA: Committee on Developments in the Science of Learning - Commission on Behavioral and Social Sciences on Education - National Research Council. Disponible en versión completa en INTERNET: http://books . nap.edu/html/howpeople1/, 2000 .

[14] Williams, M. L., Paprock, K., Covington, B., Distance Learning: The Essential Guide. London: SAGE Publications, 1999.

[15] MenA, M., La convivencia institucional de las modalidades de educación presencial y a distancia: competencia o cooperación. (En: Litwin, Edith, Maggio, Mariana y Roig, Hebe Compiladoras) Educación a Distancia en los 90. Desarrollo, problemas y perspectivas. Buenos Aires: Facultad de Filosofía y Letras de la Universidad de Buenos Aires. Programa UBA XXI, 1994.

[16] Moore, M., (Editor); Contemporany Issues in American Distance Education. Great Britain: Pergamon Press. BPCC Wheatons Ltd, Exeter. 1990. 
Received: April, 2005

Accepted: December, 2005

Contact address:

Cecilia Sanz

Faculty of Computer Science

University of La Plata

Buenos Aires, Argentina

50 and 115 street - 1st floor

La Plata - Buenos Aires

Argentina

e-mail: csanz@lidi.info.unlp.edu.ar

Alejandro Gonzalez

Faculty of Computer Science

University of La Plata

Buenos Aires, Argentina

50 and 115 street -1 st floo

La Plata - Buenos Aires

Argentina

e-mail: agonzalez@lidi.info.unlp.edu.ar

Alejandra Zangara

Faculty of Education

University of La Plata

Buenos Aires, Argentina

48 and 7 street

La Plata - Buenos Aires Argentina

e-mail: alezan@elsitio.net

Eduardo Ibañez

Faculty of Computer Science

University of La Plata

Buenos Aires, Argentina

50 and 115 street -1 st floo

La Plata - Buenos Aires

Argentina

e-mail: eibanez@lidi.info.unlp.edu.ar

Luciano Iglesias

Faculty of Computer Science

University of La Plata

Buenos Aires, Argentina

50 and 115 street -1 st floo

La Plata - Buenos Aires

Argentina

e-mail: li@info.unlp.edu.ar
Armando De Giusti Faculty of Computer Science

University of La Plata

Buenos Aires, Argentina

50 and 115 street -1 st floor

La Plata - Buenos Aires

Argentina

e-mail: degiusti@lidi.info.unlp.edu.ar

Cecilia SANZ received her doctoral degree in Computer Science from the Faculty of Exacts Science. She is a member of III-LIDI and project leader of "Distance Education Program" at the National University of La Plata, Buenos Aires, Argentina.

ALEJANDRO GONZALEZ graduated from of the Faculty of Computer Science at the National University of La Plata, Buenos Aires, Argentina. $\mathrm{He}$ is a member of III-LIDI. He works as a member of the program of "Distance Education" at the National University of La Plata.

ALEJANDRA ZANGARA received her M. A. degree in Policy and Management of Science and the Technology at CEA (Advanced Center Study). She works as a member of the program of "Distance Education" at the National University of La Plata.

EDUARDO IBAÑEZ is a student at the Faculty of Computer Science at the National University of La Plata. He is a member of III-LIDI and works as a member of the program of "Distance Education" at the National University of La Plata".

LUCIANO IGLESIAS graduated from the Faculty of Computer Science at the National University of La Plata. He is a member of III-LIDI and works as a member of the program of "Distance Education" at the National University of La Plata.

ARMANDO DE GIUSTI is the main researcher at CONICET, Argentina. Armando De Giusti is chief of the Master in Technology applied to Education at the National University of La Plata, Buenos Aires, Argentina. 